\title{
The Exploration of Strategies for Operating Facebook Fan Pages at Technical and Vocational Colleges in Taiwan
}

\author{
Chi-Hu Tien \\ Hungkuang University, Taichung, Taiwan
}

\begin{abstract}
The year 2016, impacted by the declining birth rate, was a difficult period for Taiwan's technical and vocational colleges to enroll students. The number of enrolled students declined by 14,656 compared with the 415,638 in 2015. The number of enrollment for technological and vocational schools dropped by 12,000, dwindled drastically compared with that of general universities. How to manage current students and maintain school brands to encourage student enrollment has become a focus of efforts that should be implemented by all schools? Mobile social media, such as Facebook, are valued deeply by young people across the globe. Its boundless feature has become among the cutting-edge tools employed by various schools to improve communication and their student enrollment. In addition to proposing 10 main strategies of operating Facebook fan pages for technical and vocational colleges in Taiwan, this study divides the success factors of their operations into eight under "content" and "interaction," and finally, puts forward four suggestions as a reference for the schools interested in the operation of Facebook fan pages in the future.
\end{abstract}

Keywords: Facebook fan page, social networks, school marketing

\section{Introduction}

In 2016, the total student enrollment quota for all colleges and universities in Taiwan was 400,982, which decreased by 14,656 from 415,638 in 2015 (see Table 1). Among these educational institutions, the number of technological and vocational schools decreased by 12,000, a considerable decline compared with that in general universities. In 2016, the numbers of applicants for the general scholastic ability test and technological and vocational education (TVE), and Joint College Entrance Examination presented an increasingly lower trend compared with that in 2015. In the same year, the number of applicants for the General Scholastic Ability Test reduced by 10,452 from that in 2015. The number of the TVE and Joint College Entrance Examination dropped by 13,043 , and that for technological and vocational schools had a more drastic decline compared with general universities. The decreasing enrollment and increasingly heavy operating pressure are shown in Table 1.

A survey by the social media examiner in 2016 showed that $94 \%$ of the companies surveyed used social media for marketing purposes. Fifty-eight percent of Fortune 500 companies had exclusive Facebook pages; and the five social media networking services most favored by marketing personnel were Facebook, Twitter, LinkedIn, Blogs, and YouTube. Among these social media networking services, the usage rate of Facebook was up to 92\%. The data in January 2016 indicated that the number of active Facebook users around the globe was 1.59 billion; 540 million of which was in the Asian markets, growing at a rate of $20 \%$ annually. The

Chi Hu Tien, Ph.D., assistant professor, Department of Cultural and Creative Industries, Hungkuang University. 
growth rate of the number of active Facebook users worldwide was 14\%. The number of monthly active users in Taiwan reached 17 million, taking up 74\% of the total population of Taiwan. The number of daily active users reached 13 million. From the viewpoints of Web-based users in Taiwan, more than $90 \%$ of the wired generations or netizen groups can use Facebook. Taiwan is among the markets with the highest internet permeability in the Asia Pacific region. The number of Facebook logins by each netizen is over 19 times on the monthly average, and the duration of each usage is over six hours. Facebook undoubtedly is among the most successfully developed social networking Websites around the world. In addition to its existing social functions, it also becomes a new marketing platform perceived by different sector. Its fan page is the most revolutionary.

This study selects the case school that operates a student fan page in Taiwan as the research object. To explore the approaches, they employ in operating their fan pages, and then identify the success factors of these approaches. It adopts the case study method, with in-depth interviews as the core of research. Researchers do not control or manipulate the case (school), but emphasize the understanding and analytical investigation of the cases' current situations.

Table 1

Registration for the College Entrance Examinations in Taiwan in 2015 and 2016

\begin{tabular}{|l|l|l|}
\hline Academic year/type of examination & $\begin{array}{l}\text { Number of applicants for general } \\
\text { university entrance examinations }\end{array}$ & $\begin{array}{l}\text { Number of applicants for technical and } \\
\text { vocational college entrance examinations }\end{array}$ \\
\hline 2015 & 146,035 & 136,340 \\
\hline 2016 & 135,583 & 123,297 \\
\hline
\end{tabular}

Source: Ministry of Education (2016). Data concerning ministerial presentation (bulletin). Retrieved May 2016, from https://heitoplus.edu.tw/upload/newsfs48160503241592408.pdf.

\section{Literature Review}

In the latest trend report titled “Ad Age and Creativity,” Diaz (2012) proposed three key strategies for a successful marketing of brands by utilizing Facebook, namely: (a) telling stories; (b) connecting with the real world; and (c) being user-friendly and sociable. Walter (2013) indicated that in social media, the relationship between customers and brands presented a 5L-Pyramid, starting from the lowest level, namely, lack of awareness, learn about the brand, to the levels of like, love, and even being loyal to the brand (loyalty). Social media serves as a bridge not only for marketing personnel to convey marketing information, but also for schools to promote their concepts and missions. If the marketing personnel and schools can establish successfully a long-term relationship with students which in other word customers, and then resonate with them, the customers will truly feel trusted. Once, customers are willing to endorse a certain product and even advocate it actively, the community influence will become a powerful force of dissemination by spreading the product's reputation and word-of-mouth to win the hearts of more potential customers and, ultimately, translate favorable impressions into actual actions of purchase and support. Therefore, it is easy to see that the development of social media has completely changed the relationship between customers and the branding of enterprises (Li \& Bernoff, 2008).

As found from the descriptions on the official website of Facebook, there are three main functions of Facebook for different account types. They are Personal User Account, Groups, and fan page. Both personal user accounts and groups have their own limitations. Friends have to sign up or apply if they want to view each other's contents, whereas users are allowed to enter and view the contents of groups only by clicking the "Join" 
button. A fan base as an open space does not set limits on the number of its members (Dunay \& Krueger, 2009). The information therein is completely open to the public, and users can join the fan base as they wish, as shown in Table 2 below.

Table 2

Differences Between Groups and Fan Page on Facebook

\begin{tabular}{|l|l|}
\hline Groups & Fan page \\
\hline No upper limit on the number of members. & No upper limit on the number of fans. \\
\hline Apply for joining the Groups by clicking the “Join” button. & Join by clicking the “Like” button. \\
\hline Messages can be sent to users' inbox. & Only synchronous users are allowed to update the wall. \\
\hline The degree of information openness is set by administrators. & Information is fully open. \\
\hline Does not allow the installation of application programs (APPs). & Allows the installation of APPs. \\
\hline Does not offer personalized site settings. & Offers personalized site settings. \\
\hline Does not provide user profile analysis. & Provides user profile analysis. \\
\hline
\end{tabular}

Source: Collated by this study.

As for schools, the entry threshold of the fan page is low, and its information transparency allows schools to avoid spending much energy on disseminating messages. Instead, messages can be spread naturally through a mechanism. Andrew, Graham, Mike, and Sean (2012) believed that social media should be used as a starting point to establish the relationship between schools and customers, and brands could be easily spread through the interpersonal networks that share the information. As shown in the data, all the top 100 brands introduced Facebook accounts as a marketing tool or channel, and hence, their key focus is how to attract the attention of customers by differentiation strategies. Through the sharing of brand-related knowledge, the links re-shared by fans, and the sponsor column, schools inform their prospective fans that the fan page exists.

It can also be found from the research data in relevant literature that when visiting Facebook, most people spend most of their time refreshing their Homepage, in which updates of Facebook users could be published automatically on the wall. The number time they refresh their pages is 40-150 times more than visiting a single page. Thus, schools must be fully aware of the dissemination mechanism (Lee, Xiong, \& Hu, 2012). Andrew et al. (2012) presented the value of Facebook fan page. Firstly, it increases the depth of discussions and achieves internal activeness through the ways fans interact. Secondly, it increases the purchase intention. And thirdly, it develops new consumer groups by means of leverage, namely, it enables a wider information exposure through the friends of fans, and subsequently enables to contact potential customers that are 34 times more than usual. According to the official statistics of Facebook, there are currently a total of more than 1.6 million fan pages, attracting over 530 million people to be their fans. This research pointed out that by making use of the Facebook platform operating the fan pages and groups, schools indeed to have a better understand customers' thoughts, and subsequently establish a long-term effective relationship with customers (Wu, 2009). However, the schools that have utilized successfully the Facebook fan page as a marketing tool are only in the minority.

\section{Research Findings}

The case (school) in this study created a student fan page in September 2013. By December 2016, there have been 12,080 fans on the page. In the public relation office of the case (school), there is a specially assigned staff member responsible for back-end management. Through in-depth interviews and observations, 
this study finds that the strategies by the case school in operating its Facebook fan page can be concluded as follows:

1. Organizing prize award activities at the venue of student admission exhibitions to attract new fans.

At the exhibition venue of each admission promotion, set up a quick response (QR) code signboard for joining the fan page. Students will be given small gifts provided that they join as fans.

2. Playing prize award games with fans (members) to increase interactions.

Whenever a prize award is held, there is often a widespread response attracting new fans to join, and partly to maintain the activeness of existing fans.

3. To attract responses from fans by sharing videos or movies.

The video with images and sounds is the most popular form of message appreciated by the community of fans. Research findings indicated that such type of messages could receive the greatest number of responses. Currently, there are 12,080 fans for this study, and the average rate of clicking through image-based messages is over $10 \%$. A number of movies or videos may also be reproduced or reposted, making the number of clicks exceed that of fans.

4. Photo sharing enriches the web screen of fan pages.

The photos that record vividly the highlights of organizational work are the Wall messages that are also warmly welcomed by the fans. They are easier to produce than movies, and an optimal marketing and promotional effect will be reached, provided that a simple textual description of the photos is given.

5. News sharing enriches the contents.

The resonance from community members can also be obtained by reposting or sharing news links relevant to the organization's mission, and expressing opinions from the professional perspective of the organization's long-term attention to a certain issue.

6. Blogging to get close to the fans' daily life.

Blogging is similar to news sharing, but it is designed to report the activity highlights of the school in a relaxed style or tone, and it often receives pretty good responses. However, blogs should not be too lengthy.

7. Reposting APP games to enhance the stickiness of young students.

Through the observation of other organizations' approaches to operating fan bases, this study found that creating an interesting APP indeed can attract people effectively. However, the creation of APP requires a certain level of professional knowledge and skills, which are beyond the capabilities of the school's management units. Hence, reposting the currently popular APP games has become among the ways to attract the attention of student fans.

8. Creating an introduction page tag to attract the attention of fans.

Create an attractive link to the page tag on the school's official website to enable non-community members to access the Fans Page easily. Subsequently, view the most powerful message conveyed by the school.

9. Using strings of stickers to expand the circle of friends.

Strings of stickers may facilitate loyal community members to post organized activities within their own social circle. On average, each Facebook user has 150 friends, all of whom have 150 friends of their own. If such cascades continue, the breadth of information dissemination will be considerable.

10. Expanding the influence by incorporating blogs.

As Facebook presents its message in time stream as the concept, the message is unable to be presented for 
a long time, and it is impossible to search old information by keywords on Facebook. Therefore, the combination of blogs with the operation of a Facebook fan page is a thoughtful practice agreed by the operators of various organizations. It is designed to avoid the disappearance of information that is worth preserving for a long time.

By synthesizing the views of the respondents, the factors for a successful operation of a Facebook fan page and achieving good marketing effects can be summarized as "content" and "interaction" orientations.

The "content" includes the following:

1. Using videos and photos to enhance the vividness and attractiveness of contents;

2. The use of multidimensional links to achieve a comprehensive effect;

3. Posting blog articles written in a tone close to fans;

4. Adequate frequency of news and blog posting maintain the stickiness of fans;

5. The information or message should be relevant to the fans to initiate discussions, and the information can be forwarded.

The "interaction" includes:

1. Respond earnestly to the opinions of members;

2. Encouraging fans to participate, by using APP, conducting activities, and offering favorable discounts as incentives to stimulate customer participation;

3. Stimulate discussions; for example, ask about the experiences and feelings of certain activities.

A fan page brings a number of positive benefits to the student admission personnel. The current upsurge in Facebook usage in Taiwan can make it even more popular in the future. Along with the maturity and diversity-oriented nature of application technologies, the fan page will have a more comprehensive development in school marketing.

\section{Conclusions and Discussions}

Subsequent to the integration of research findings, this study provides specific suggestions below regarding how technical and vocational colleges in Taiwan can operate successfully the Facebook fan pages of their students:

1. Schools should invest their resources in the operation of a Facebook fan page.

Except those in mainland China, the students in almost all countries around the world have Facebook accounts. In addition to the currently booming development of community environment, a more important reason for the motivation of schools to operate students' Facebook fan page is that the fan page can serve as a boundless and remote channel for an in-depth communication with students in and outside Taiwan, which considerably helps in improving the degree of preference for schools and increasing the incentives for schooling. Schools with abundant resources may deploy their own human resources for operations, to maintain the speed of website updates, create an exclusive APP, or send free gifts to obtain fans. Schools with insufficient resources may form an alliance using the fan page, create mutual recommendations, or use free APPs.

2. To increase the number of fans is the core of work.

The number of fans is critical to the success of Facebook fan page. Hence, the core work in operating a fan page should be how to increase the number of fans. The strategies that could be employed include gift-giving activities, App downloads, or the development and provision of links to mini-games. 


\section{A variety of strategies should be employed to maintain the stickiness of fans.}

Although school reputation played an important role in increasing the number of fans during the initial period, the subsequent interactions with fans and the managers' commitment to operate are the key reasons for the lasting success of Facebook fan pages. The students joined the Facebook fan page of a school mainly to meet their functional demands, and thus, the operations of a fan page should focus on satisfying the functional demands of fans for information and entertainment, among others. After fulfilling the functionality of the fan page, the next step is to meet the fans' social demand, that is, to create a highly interactive environment in which fans can enjoy fully the freedom of speech on the fan pages, and are willing to discuss and exchange views with each other. If a school can make students feel a high sense of belonging for the fan page, and enable them to perceive their own values and, subsequently, become an enthusiastic follower of the Page, the influence of relevant contents and messages through the word-of-mouth recommendations from the groups of enthusiastic followers will expand.

4. The member information of Facebook fans should be analyzed regularly to be aware fully of the members' preferences that are subsequently regarded as the basis for continuous improvement.

It is important to understand and learn how to analyze the "profile data of members." In addition, maintaining a good customer relationship and improving "member loyalty" are also the main reasons for the continuous growth of a Facebook fan page (Chen, 2011). Another point that makes a fan page attractive to schools is that it provides its administrators with a complete and a free-of-charge "precision marketing data analysis" function. Through this function, school personnel can grasp easily the attribute of community members' composition and the state of their interactions, which subsequently become the important bases for schools to examine their admission effectiveness and then adjust marketing strategies accordingly.

\section{References}

Andrew, L., Graham, M., Mike, R., \& Sean, B. (2012). The power of "like” how brands reach (and influence) fans through social-media marketing. Journal of Advertising Research March, 52(1), 40-52.

Armstrong, A. G., \& Hagel, J. III. (1996). The real value of on-line communities. Harvard Business Review, 74(3), 21-28.

Chen, Z. Y. (2011). The study of social media marketing for the nonprofit organizations: A case study of Facebook (M.A. thesis, Graduate Institute of Cultural and Educational Management; Central Taiwan University of Science and Technology, Taichung City).

Diaz, A. C. (2012). Facebook 101: Is your brand worth a like? Advertising Age, 83(5), 6.

Dunay, P., \& Krueger, R. (2009). Facebook marketing for dummies. Nan Jing, N.J.: Wiley.

Lee, W., Xiong, L., \& Hu, C. (2012). The effect of Facebook users' arousal and valence on intention to go to the festival: Applying an extension of the technology acceptance model. International Journal of Hospitality Management, 31(3), 819-827.

Li, C., \& Bernoff, J. (2008). Groundswell: Winning in a world transformed by social technologies. Boston, M.A.: Harvard Business Press.

Ministry of Education. (2016). Ministerial presentation (bulletin). Retrieved December 10, 2016, from https://heitoplus.edu.tw/upload/newsfs48160503241592408.pdf

Social Media Examiner. (2016). Retrieved December 10, 2016, from https://www.socialmediaexaminer.com/wpcontent/uploads/2016/05/ SocialMediaMarketingIndustryReport2016.pdf

Walter, E. (2013). Eight essentials of creating a sustainable advocacy program. Retrieved December 20, 2016, from http://socialmediatoday.com/ekaterina/1767886/8-essentialscreating-sustainable-advocacy-program

Wu, F. J. (2009). The enterprises operate the virtual community by using Facebook fans page master thesis, graduate institute of technology, innovation, and intellectual property management. Taipei: National Chengchi University. 